\title{
XXVIII. Method of ventilating mines or hospitals, by extracting the foul air from them
}

\author{
Mr. John Taylor
}

To cite this article: Mr. John Taylor (1811) XXVIII. Method of ventilating mines or hospitals, by extracting the foul air from them , Philosophical Magazine Series 1, 38:160, 120-127, DOI: 10.1080/14786441108638617

To link to this article: http://dx.doi.org/10.1080/14786441108638617

$$
\text { 册 Published online: } 27 \text { Jul } 2009 .
$$

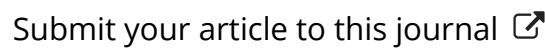

Џ Article views: 2 


\section{[ 120$]$}

XXVIII. Method of Ventilating Mines or Hospitals, by extracting the foul Air from them. By Mr. Јон TAYLOR, of Holwell-House, near Tavistock*.

Sir, I SEND you herewith a drawing and description of a machine of my invention for the ventilation of mines, with a view to their being laid before the Society for the Encouragement of Arts, \&c. and hope they will meet with their approbation.

Holwell, April 9, 1810. I am, sir,

Your obedient servant, JohN TAYLOR.

To C. Taylor, M.D. Sec.

On the Ventilation of Mines, with the Description of a new Machine for that Purpose. See Pl. IV. Fig. 3.

Next in importance to the means employed for draining underground works from water, may be reckoned those which are intended to afford a supply of pure air, sufficient to enable the workmen to continue their operations with ease and safety to themselves, and to keep up, undiminished, the artificial light unon which they depend. It is well known, indeed, to all who are practically engaged in concerns of this kind, that men are frequently obliged to persevere in their labour, where a candle will scarcely burn, and where not only their own health materially suffers in the end, but their employers are put to considerable additional expense by the unavoidable hindrance and the waste of candles and other materials.

I mean to confine the following remarks to such mines as are worked upon metalliferous veins, according to the practice of this district, and that of the great seat of mining in the neighbouring county of Cornwall, from which indeed ours is borrowed. We find then that a single shaft, not communicating by levels to another, can hardly be sunk to any considerable depth, nor can a level (or, as the foreign miners call it, a gallery) be driven horizontally to any great distance, without some contrivance being had recourse to for procuring currents of air to make up the deficiency of oxygen, which is so rapidly consumed by respiration and combustion in situations like these, where otherwise the whole remains in nearly a stagnant condition.

* From Transactions of the Society for the Encouragement of Arts, Mronyfac: tures, and Commerce, for 1810 . The Society's silver medal was voted to Mr. John Taylor for this communication. 
Mr. Moults Filtering Apparatus.

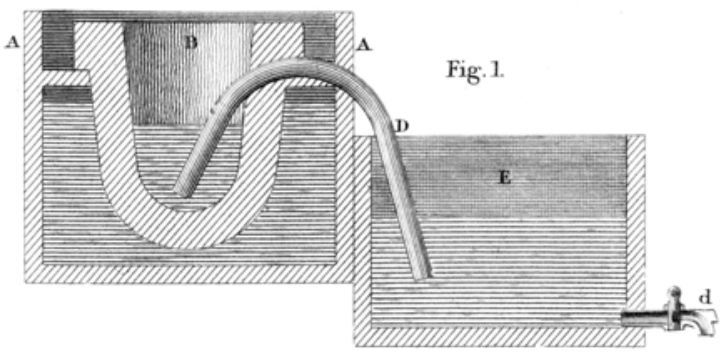

Mr. Smith's method of relieving a Horse which has fallen in the shaft of a loaded Cart.

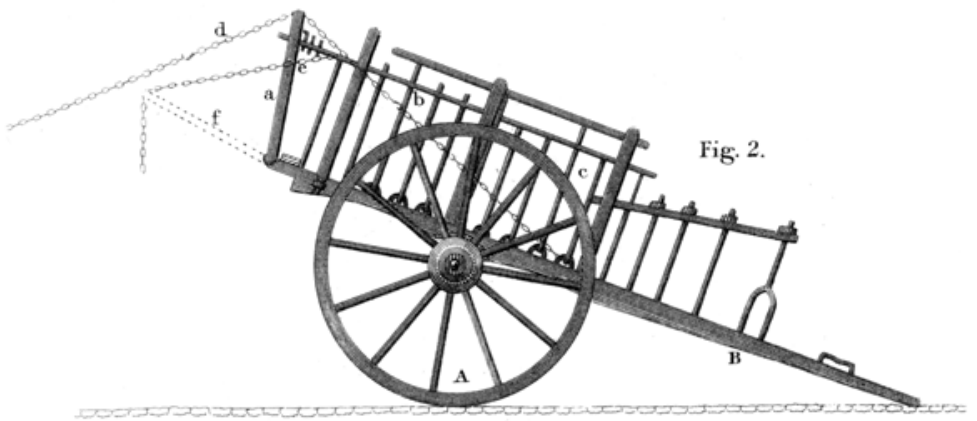

M. Taylor's dir Exhauster for Mines.

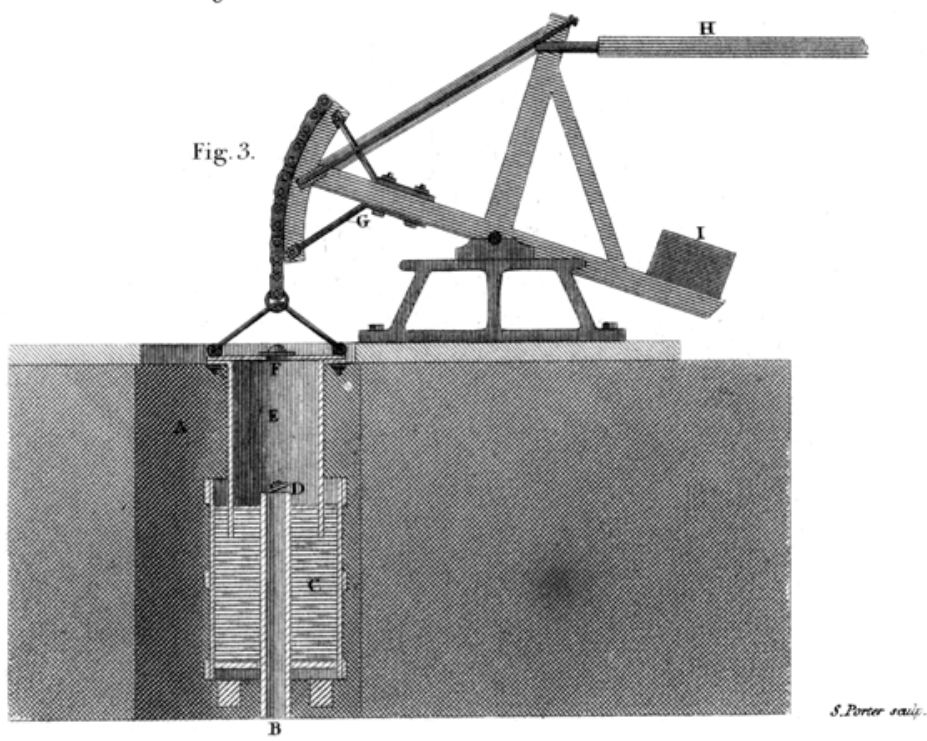


We are here unacquainted with the rapid production of those gases which occasionally in the collieries are the cause of such dreadful effects; such as hydrogen gas, or the firedamp; carbonic acid, or the choke-damp; the inconvenience we experience takes place gradually as we recede from the openings to the atmosphere, and seems to arise solely from the causes which I have before assigned, though it is found to come on more rapidly in certain situations than in others.

The most obvious remedy, and that which is most frequently resorted to, is the opening a communication either to some other part of the mine, or to the surface itself; and as soon as this is done, the ventilation is found to be complete, by the currents which immediately take place, often with considerable force, from the different degrees of temperature in the subterranean and upper atmospheres; and these currents may be obscrved to change their directions as the temperatures alternate.

The great objection to this mode of curing the evil is, the enormous expense with which it it most commonly attended. In driving a long level, or tunnel, for instance, it may happen to be at a great depth under the surface, and the intervening rock of great hardness; in such a case every shaft which must be sunk upon it for air alone, where not required (as often they might not) to draw up the waste, would cost several hundred pounds; or in sinking a shaft it mav be necessary, at an expense not much less, to drive a level to it from some other for this purpose alone.

To avoid this, recourse has been had to dividing the shaft or level into two distinct parts, communicating near the part intended to be ventilated, so that a current may be produced in opposite directions on each side the partition; and this, where room is to be spared for it, is often effectual to a certain extent. It is found, however, to have its limits at no very great distance, and the current at best is but a feeble one, from the nearly equal states of heat in the air on each side. The only scheme besides these, that I know of, has hitherto been to force down a volume of purer air, through a system of pipes placed for the purpose, and a variety of contrivances have been devised for effecting this; most of them are so old that they may be found described in Agricola's work De Re Metallicá. The most common are by bellows worked by hand; by boxes or cylinders of various forms placed on the surface with a large opening against the wind, and a smaller one communicating with the air-pipes by a cylinder and piston working in it, which when driven hy a sufficient force has great power. But the cheapest 
cheapest and most effectual scheme for this purpose, where circumstances will admit of its being applied, is one which I adopted some tine since in the tunnel of the Tavistock canal. It is by applying the fall of a stream of water for this purpose, and it has been long known that a blast of considerable strength may be obtained in this manner, which has the advantage of being constant and self acting. The stream being turned down a perpendicular column of pipes, dashes in at a vessel so contrived as to let off the water one way, with an opening at another part for the air, which being pressed into it by the falling water, may be conveyed in any direction, and will pass through air-pipes with a strong current, which will be found efficacious in ventilating mines in many instances, as it has likewise, in some cases, been sufficient for urging the intensity of fires for the purposes of the forge. It is easily procured where a sufficient fall is to be had; and the perpendicular column can be so fixed as that the water from the bottom may pass off, while the air is forced into a pipe branching from the air-vessel, and which is to be continued to the part of the mine where the supply of fresh air is required.

I have found, however, that the furcing into vitiated air a mixture of that which is purer, even when the best means are used, though a measure which affords relief, is not in bad cases a couplete remedy; and, where the operation depends on manual labour, or any means that are not unremitted in their action, it becomes quite ineffectual. The foul air, charged with the smoke of gunpowder used in blasting, and which it strongly retains, is certainly ameliorated by the mixture of pure air, but is not removed. While the blast continues, some of it is driven into the other parts of the mine; but when the influx of pure air ceases, it returns again: or if during the influx of pure air a fresh volume of smoke be produced by explosions which are constantly taking place, it is not until some time afterwards that it becomes sufficiently attenuated for the workmen to resume their stations with comfort.

A consideration of these circumstances led me to think that the usual operation of all ventilating engines ought to be reversed, to afford all the advantages that could be desired; that, instead of using the machines which serve as condensers, exhausters should be adopted; and thus, instead of forcing pure air into that in a vitiated state, a complete remedy could only be had by pumping out all that was impure as fast as it became so.

Many modes of doing this suggested themselves to me, 
by the alteration of the machines commonly applied, and by producing an ascending stream of air through pipes by a furnace constructed for the purpose. The latter mode would, however, have been here expensive in fuel as well as in attendance; and the others required power to overcome the friction of pistons, and so on, or considerable accuracy in construction.

I at last erected the machine, of which the annexed is a drawing; which, while it is so simple in construction, and requires so small an expense of power, is so complete in its operation, and its parts are so little liable to be injured by wear, that, as far as I can imagine, nothing more can be desired where such an one is applied. This engine bears considerable resemblance to Mr. Pepys's gazometer, though this did not oceur to me until after it was put to work. It will readily be understood by an inspection of the drawing, (Pl. IV. fig. 3,) where the shaft of the mine is represented at $A$; and it may here be observed, that the machine may be as well placed at the bottom of the shaft as at the top, and that in either case it is proper to fix it upon a floor, which may prevent the return of the foul air into the mine, after being discharged from the exhauster: this floor may be furnished with a trap-door, to be opened occasionally for the passage of buckets through it.

$B$, the air-pipe from the mine passing through the bottom of the fixed vessel or cylinder $\mathrm{C}$, which is formed of timber and bound with iron hoops ; this is filled with water nearly to the top of the pipe $B$, on which is fixed a valve opening upwards at $\mathrm{D}$.

$\mathrm{E}$, the air-or exhausting-cylinder made of cast-iron, open at the bottom and suspeuded over the air-pipe, immersed some way in the water. It is furnished with a wooden top, in which is an opening fitted with a valve likewise opening upwards at $F$.

The exhausting-cylinder has its motion up and down given to it by the bob G, connected to any engine by the horizontal rod $\mathrm{H}$, and the weight of the cylinder is balanced, if necessary, by the counterpoise I.

The action is obvious. - When the exhausting-cylinder is raised, a vacuum would be produced, or rather the water would likewise be raised in it, were it not for the stream of air from the mine rushing throngh the pipe and valve $D$. As soon as the cylinder begins to descend, this valve closes, and prevents the return of the air which is discharged through the value $F$.

The quantity of air exhausted is calculated of course from the 
the area of the bore of the cylinder, and the length of the stroke.

The dimensions which I have found sufficient for large works are as tullow:

The bore of the exhausting cylinder two feet.

The length six feet, so as to afford a stroke of four feet.

The pipes which conduct the air to such an engine ought not to be less than six inch bore.

The best rate of working is from two to three strokes a minute; but if required to go much faster, it will be proper to adapt a capacious air-vessel to the pipes near the machine, which will equalize the current pressing through them.

Such an engine discharges more than two hundred gallons of air in a minute; and I have found that a stream of water supplied by an inch and a balf bore falling twelve feet, is sufficient to keep it regularly working.

A small engine to pump out two gallons at a stroke, which would be sufficient in many cases, could be worked by a power equal to raising a very few pounds weight, as the whole machine may be put into complete equilibrium before it begins to work, and there is hardly any other friction to overcoine but that of the air passing through the pipes.

The end of the tunnel of the Tavistock canal, which it was my object to ventilate, was driven into the hill to a distance of near three hundred yards from any opening to the surface; and being at a depth of one hundred and twenty yards, and all in hard schistus rock, air-shafts would have been attended with an enormous expense; so that the tunnel being a long one, it was most desirable to sink as few as possible, and of course at considerable distances from each other. Thus a ventilating machine was required, which should act with sufficient force through a length of near half a mile; and on the side of the bill where it first became necessary to apply it, no larger stream of water to give it motion could be relied on, than such an one as I have mentioned after the description of the engine, and even that flowed at a distance from the shaft where the engine was to be fixed; which made a considerable length of connexionrods necessary.

Within a very short time after the engine began to work, the superiority of its action over those formerly employed was abundantly evident. The whole extent of the tunnel, which had been uninterruptedly clouded with smoke for some months before, and which the air that was forced in never could drive out, now became speedily so clear, that the day-light and even objects at its mouth were distinctly 
seen from its furthest end. After blowing up the rock, the miners could instantly return to the place where thev were emploved, unimpeded by the smoke, of which no appearance would remain underground in a very few muntes, while it might be seen to be discharged in gusts, from the valve at the top of the shaft. The constant current into the pipe, at the same time effectually prevented the accumulation of air unfit for respiration. The influx of air, from the level into the mouth of the pipe, rushes with such force as instantly to extinguish the flane of a large candle; and any substance applied, so as to stop the orifice, is held tight by the outward pressure.

It is now mare than two years since the machine was erected, and it has been uninterruptedly at work ever since, and without repair. The length of the tunnel has been nearly doubled, and the pipes of course in the same proportion, and no want of ventilation is yet perceptible.

Two similar en yines have been since constructed for otber parts of the same cunnel, and have in every respect answered the purpose for which they were designed.

The original one is worked by the small stream of water before mentioned, by means of a light overshot-w heel twelve feet in diameter, and about six inches in breast.-The two others are attached to the great overshot-wheel which pumps the water from the shafts which are sinking upon the line; and as their friction is comparatively nothing, this may be done in any case, with so little waste of power for this purpose as not to be an-object of consideration, even if the power be derived from more expensive means.

The size of the exhauster may always be proportioned to the demand for air ; and by a due consideration of this circumstance, this engin: may be effectually adapted not only to mines and collieries, but also to manufactories, workhouses, hospitals, prisons, ships, and so on.

Thus, if it were required to ventilate a shaft of a mine, or a single level, which is most frequently the case, where three men are at work at one time, and we allow that those three men vitiate each twenty-seven and a half cubic inches of air per minute, (as determined by the experiments of Messrs. Allen and Pepys,) and allowing further that their candles vitiate as much as the men, there will be six times twenty-seven and a half cubic inches of air to be drawn out in a minute, equal to one hundred and sixty-five.

Now a cylinder five inches in diameter, working with a stroke at nine inches, will effect this by one struke in a mi- 
nute; though it would certainly be advisable to make it larger.

Not being practically acquainted with collieries, or mines that suffer from peculiar gases that are produced in them, I cannot state, from actual experiment, what effect this machine might have in relieving them; but it must appear, I conceive, evident to every person at all acquainted with the first principles of pneumatics, that it must do all that can be wished, as it is obvious that such a machine must in a given time pump out the whole volume of air contained in a given space, and thus change an impure atmosphere for a better one. And in constructing the machine it is only necessary to estimate the volume of gas produced in a certain time, or the capacity of the whole space to be ventilated. It is easy to judge how much more this must do for such cases as these, than such schemes as have lately been proposed of exciting jets of water, or slaking lime, both of which projects, likewise, must fail when applied; as one of them has, I believe, when applied to the case of hydrogen gas. But with such a machine as this; if the dreadful effects of explosions of this air are to be counteracted, it may be done by one of sufficient size to draw off this air as fast as it is generated; and by carrying the pipes into the elevated parts of the mine, where from its lightness it would collect. If, on the other hand, it is desired to free any subterraneous work from the carbonic acid gas, it may as certainly be done by suffering the pipe to terminate in the lower parts, where this air would be directed by its gravity.

In workbouses, hospitals, manufactories, \&c. it is always easy to calculate the quantity of air contained in any room, or number of rooms, and easy to estimate how often it is desirable to change this in a certain number of hours, and to adjust the size and velocity of the engine accordingly. Where this change of foul air for pure is to take place in the night, means for working the machine may be provided by pumping up a quantity of water into a reservoir of sufficient height to admit of its flowing out during the night in a small stream, with sufficient fall, so as to give motion to the engine; or by winding up a weight of sufficient size, or by many other means which are easily devised.

If, for instance, a room in which fifty persons slept was eighty feet long, twenty wide, and ten high, it would contain 16,000 cubic feet of air, and if this was to be removed twice in eight hours, it would require a cylinder of thirty inches diameter, working with a four-feet stroke four times 
in a minute, to do it ; or nearly that. Such a cylinder could be worked by the descent of ten gallons of water ten feet in a minute; or, for the whole time, by eighty bogsheads falling the same height.

But this is a vast deal more than could be required, as the fifty people $n$ ould in eight hours vitiate only three thousand gallons of air, which could be removed by one hindred and fifty strnkes of a cylinder, twelve inches diameter, with a four-feet stroke, which would not require an expenditure of more than one thousand five hundred gallons of water properly applied, or about twenty-eight hogsheads.

Holwell, near Tavistock, Feb. 7, 1810.

JoHN TAYLOR.

XXIX. Description of an improved Micrometer. By E. Walker, Esq.

\section{To $M r$. Tilloch.}

Sir, $A_{\mathrm{N}}$ exact method of taking small angles is a subject of the greatest importance in various branches of practical astronomy and philosophy. For this purpose the micrometer was invented, which has been constructed of various forms and on different principles; but even the best of them are very complex in their construction, and consequently too expensive to be of general utility.

To obviate these inconveniences $\mathrm{Mr}$. Tiberius Cavallo invented the telescopic mother-of-pearl micrometer, "which consists of a small semitransparent slip of mother-of-pearl about the 2oth part of an inch broad, and of the thickness of common writing-paper, divided into a number of equal parts by parallel lines." A full description of this micrometer and the uses to which it may be applied have been published in the 81 st volume of the Philosophical Transactions for the year 1791 , and in a separate pamphlet published in 1793.

This simple instrument possesses many valuable properties; and when the extremities of the object to be measured fall exactly upon two lines of the scale, it is very accurate: but as the fractional parts of a division on the scale cannot be known but by estimation, it falls far short of that accuracy which is obtained by other micrometers.

The micrometer that I have contrived is constructed at a small expense, and yet it is very accurate. It consists of a number of parallel lines drawn upon a piece of plane glass 